\title{
Analysis of SYT-SSX Fusion Transcripts and bcl-2 Expression and Phosphorylation Status in Synovial Sarcoma
}

\author{
Tommaso Mancuso, Alessandra Mezzelani, Carla Riva, Alessandra Fabbri, \\ Laura Dal Bo, Giuseppe Sampietro, Paola Perego, Paolo Casali, Franco Zunino, \\ Gabriella Sozzi, Marco A. Pierotti, and Silvana Pilotti
}

Division of Anatomic Pathology and Cytology (TM, AM, CR, AF, GSa, SP), Experimental Oncology B (LDB, PP, FZ), Medical Oncology A (PC), and Experimental Oncology A (GSo, MAP), Istituto Nazionale per lo Studio e la Cura dei Tumori, Milano, Italy

SUMMARY: Synovial sarcomas (SS) are characterized by a chromosomal translocation $t(X ; 18)(p 11.2 ; q 11.2)$ which usually fuses the SYT gene from chromosome 18 to SSX1 or SSX2 genes on chromosomeX. Also, a variant SYT-SSX4 fusion gene has recently been shown in a single SS case. In addition to these cytogenetic changes, bcl-2 expression, as assessed by immunohistochemistry, has been reported to be an almost general constitutive alteration of SS. In the present work, we analyze a series of 36 SS surgical samples (from 34 patients) by RT-PCR for the presence of the SYT-SSX1 or the SYT-SSX2 fusion transcript. The analysis was extended to SYT-SSX4 on SYT-SSX1-negative and SYT-SSX2-negative cases only. Our results showed a significant correlation between the SYT-SSX2 fusion and the monophasic SS histologic subtype. SYT-SSX1 fusion transcripts were present in both monophasic and biphasic tumors. The SYT-SSX4 fusion type was detected in a single monophasic SS. In the same series of SS cases, we also confirmed and extended the previously reported constitutive expression of bcl-2 protein, by using both immunohistochemical and western blot analysis. Moreover, we demonstrated that the BCL-2 gene is not rearranged or amplified at genomic level, indicating that the high levels of bcl-2 expression observed in SS might result from transcriptional activation of the gene and/or protein stabilization. Finally, we show that bcl-2 is not phosphorylated in tumors from patients who had been preoperatively treated with radio/chemotherapy, in tumors from untreated patients, or in an SS cell line (CME-1) after in vitro treatment with cytotoxic concentrations of DNA-damaging agents or taxanes. These data indicate that SS cells are unable to activate an apoptosis pathway involving bcl-2 phosphorylation/inactivation and may provide a possible explanation for the limited effectiveness of conventional pharmacological treatments of this tumor type. (Lab Invest 2000, 80:805-813).

$S$ ynovial Sarcoma (SS), a malignant lesion that typically arises in the para-articular regions of adolescents and young adults, is cytogenetically characterized by a translocation $t(X ; 18)(p 11.2 ; q 11.2)$, which is detectable in more than $90 \%$ of the total cases (Sreekantaiah et al, 1994). This chromosomal rearrangement generally fuses the SYT gene from chromosome 18 to either SSX1 or SSX2 genes on chromosome X (Clark et al, 1994; de Leeuw et al, 1995), resulting in the formation of chimeric proteins with transcriptional regulation functions and nuclear localization (Brett et al, 1997; dos Santos et al, 1997). Lately, another member of the SSX gene family, SSX4, has been reported to fuse with $S Y T$ in a single case of SS (Skytting et al, 1999). A model of SS molecular pathogenesis has been proposed in which the aminoterminal domain of SSX proteins could inhibit the transcription of specific target genes in normal tis-

Received December 7, 1999.

Address reprint requests to: Dr. S. Pilotti, Chief of the Division of Anatomical Pathology and Cytology, Istituto Nazionale per lo Studio e la Cura dei Tumori, via G. Venezian 1, 20133 Milano, Italy. Fax: 39022390756. E-mail:pilotti@istitutotumori.mi.it sues. In neoplastic lesions, the amino-terminal portion of SSX proteins is replaced with the transcriptional activation amino-terminal domain of SYT, which confers the capacity to direct the transcription of previously repressed genes to the chimeric protein (Brett et al, 1997; dos Santos et al, 1997). However, since both SYT and SSX seem to lack a DNA-binding activity, their transcriptional activity is thought to occur through interaction with yet unknown regulatory nuclear factors. Also, the genes normally repressed by SSX1, SSX2, or SSX4 and activated by the SYT-SSX fusion proteins are still unidentified.

Histologically, SS are subcategorized into biphasic tumors, which contain both epithelial and spindle cells, and monophasic tumors, which are entirely formed by spindle cells (Enzinger and Weiss, 1995). A recent work reported a significant correlation between the type of SYT-SSX fusion transcript and the clinical behavior of SS (Kawai et al, 1998). The shorter metastasis-free survival of SYT-SSX1-carrying cases, however, was difficult to ascribe to one of these two SS histological subtypes, because of the similar contribution of biphasic and monophasic tumors (12 and 17 , respectively). 
Recently, we and other investigators reported that bcl-2 expression, as assessed by immunohistochemistry (IHC), is an additional constitutive hallmark of almost all SS (Hirakawa et al, 1996; Pilotti et al, 1998; Suster et al, 1998), with immunoreactivity for bcl-2 protein mainly restricted to the spindle cell component of these tumors. The overexpression of bcl- 2 has been implicated in blocking apoptosis induced by a multitude of different stimuli (Korsmeyer, 1992; Reed, 1994). At the embryonic level, bcl-2 protein expression has been observed in cells with a long life and/or a proliferating ability, such as cells undergoing a morphological transition from undifferentiated stem cells to committed precursor cells (Lu et al, 1993b). The activation of the $B C L-2$ protooncogene was originally observed in concomitance with the chromosomal translocation $\mathrm{t}(14 ; 18)(\mathrm{q} 32 ; \mathrm{p} 21)$, as revealed in human follicular lymphoma (Bakhshi et al, 1985; Tsujimoto et al, 1985). bcl-2, however, is also overexpressed in a variety of other tumors that lack this typical chromosomal alteration (Lu et al, 1993a; Pezzella et al, 1993). In addition, the expression of bcl-2 seems to be under hormonal control in normal tissues (Tilly, 1996), where it participates in hormone-dependent tissue remodelling, and in breast, endometrial, and prostate cancers (Apakama et al, 1996; Ferrieres et al, 1997; Taskin et al, 1997). Finally, bcl-2 expression has been implicated in drug responsiveness, since the ability of some chemotherapeutic agents to induce phosphorylation of bcl-2 has been assumed as a mechanism by which they can suppress the anti-apoptotic activity of bcl-2, and thus promote cell death (Haldar et al, 1996).

In the present work, we characterized a series of 36 SS surgical samples for morphology and type of fusion transcript, to examine possible correlations between the type of SYT-SSX fusion and the SS histologic subtype. In addition, we wanted to confirm the previous IHC-based observation of bcl-2 expression in the great majority of SS tissue samples, and to extend this analysis with western blotting. Moreover, we examined whether the high levels of bcl-2 protein could be due to $B C L-2$ gene amplification or rearrangement. Finally, we investigated the bcl-2 phosphorylation status in these cases and in SS in vitro cultured cells, because of its reported influence on the anti-apoptotic effect of bcl-2 and in the light of the moderate drug responsiveness of SS patients.

\section{Results}

\section{Type of SYT-SSX Fusion Transcript}

We analyzed 36 SS surgical samples (21 monophasic and 15 biphasic) from 34 patients (Table 1). The presence of SYT-SSX fusion transcript in three cases [patients \#10, \#22, and \#34 (tumor relapse)] was not evaluated by RT-PCR because of the poor quality of the mRNA (as checked by amplification of $\beta$-actin). In patients \#1, \#7, and \#11, SYT-SSX1 and SYT-SSX2 fusion transcripts were absent, although $\beta$-actin mRNA was successfully amplified. We then evaluated the presence of SYT-SSX4 fusion type in these three cases as recently described (Skytting et al, 1999), and obtained a positive result for patient \#1 only. In the remaining two cases, for which the pathologist assured an unquestionable diagnosis of SS, a translocation $t(X ; 18)$ could either have not occurred or could have generated truncated (Sonobe et al, 1999) or alternative forms of the fusion transcripts. However, fusion transcripts other than SYT-SSX1, SYT-SSX2, or SYT-SSX4 have not previously been reported in SS.

Of the remaining 30 samples (17 monophasic and 13 biphasic), 20 (66.7\%) had an SYT-SSX1 fusion transcript and $10(33.3 \%)$ had an SYT-SSX2 fusion transcript. This ratio is consistent with those already reported in previous studies (Crew et al, 1995). The results of statistical comparison of fusion types and clinicopathologic features are given in Table 2. Twelve of the 13 biphasic tumors showed an SYT-SSX1 fusion type, whereas the 17 monophasic tumors were almost equally distributed in the SYT-SSX1-positive and SYT-SSX2-positive categories (8 and 9 cases, respectively). The $p$ value for this association was 0.01 (Fisher's exact test). Other $p$ values considered in the present study were not significant.

\section{bcl-2 Immunoreactivity}

Immunohistochemical bcl-2 reactivity was consistently observed in 17 of 19 primary tumors, 6 relapses, and 11 metastases (10 pulmonary and 1 adrenal gland) (Table 1). Such immunoreactivity was common to almost all tumor cells in monophasic SS, whereas it was restricted to the spindle cells in all biphasic tumors (Fig. 1, a and b). Interestingly, the two primary tumors that were negative for bcl-2 IHC analysis did not show any of the three SYT-SSX fusion variants (patients \#7 and \#11).

Western blot immunoreactivity for the $26 \mathrm{kd}$ bcl-2 protein (Fig. 2) was found in 35 of the 36 samples analyzed (Table 2), with a tendency to show a stronger signal in monophasic (20 samples) than in biphasic (15 samples) tumors. This is probably due to the fact that the sarcomatous spindle cell component in biphasic cases was not microdissected to prepare protein lysates for western blot analysis, and bcl-2 molecules were diluted by the negative epithelial component. The concordance between IHC and western blot results was good, as the two IHC negative cases (\#7 and \#11) did not show very high levels of bcl-2 protein by western analysis. There was no correlation between bcl-2 protein levels as assessed by western analysis and the type of fusion transcript (Table 2).

None of the 36 samples analyzed by western blot showed the presence of slower-migrating phosphorylated bcl-2 bands, which appeared as a smear in the upper part of the band in control taxol-treated human breast cancer MCF-7 cell line (Fig. 2). In three of the 36 cases (patients \#12, \#16, and \#20), a second immunoreactive, faster-migrating protein was observed (see case \#12 of Fig. 2). In these samples, the cDNA region encompassing amino acids 16 to 173 of bcl-2 showed no deletions or premature stop codons (data not shown). Thus, the lighter bands revealed by west- 
Table 1. Clinicopathological, Molecular, Immunophenotypical, and Biochemical Features in 34 SS Cases

\begin{tabular}{|c|c|c|c|c|c|c|c|}
\hline $\begin{array}{l}\text { Patient } \\
\text { No. }\end{array}$ & $\begin{array}{c}\text { Sample } \\
\text { Analyzed }^{a}\end{array}$ & Age/Sex & Morphology & $\begin{array}{l}\text { Fusion } \\
\text { Transcript }\end{array}$ & $\begin{array}{l}\text { bcl-2 (IHC } \\
\text { Analysis) }\end{array}$ & $\begin{array}{c}\text { bcl-2 (Western Blot } \\
\text { Analysis) }\end{array}$ & $\begin{array}{c}\text { bcl-2 } \\
\text { Phosphorylation }\end{array}$ \\
\hline 1 & $P$ & $48 / F$ & Monophasic & SYT-SSX 4 & + & +++ & NO \\
\hline 2 & $\mathrm{P}$ & $36 / F$ & Monophasic & SYT-SSX 2 & + & +++ & NO \\
\hline 3 & $P$ & $46 / F$ & Monophasic & SYT-SSX 1 & + & ++++ & NO \\
\hline 4 & $P$ & $48 / F$ & Monophasic & SYT-SSX 2 & + & ++++ & NO \\
\hline 5 & $P$ & $39 / F$ & Monophasic & SYT-SSX 2 & + & ++++ & NO \\
\hline 6 & $P$ & $43 / \mathrm{M}$ & Monophasic & SYT-SSX 2 & + & ++++ & NO \\
\hline 7 & $P$ & $56 / F$ & Monophasic & Absent & - & ++ & NO \\
\hline 8 & $P$ & $18 / \mathrm{M}$ & Biphasic & SYT-SSX 1 & + & ++ & NO \\
\hline 9 & $P$ & $36 / \mathrm{M}$ & Biphasic & SYT-SSX 1 & + & ++ & NO \\
\hline 10 & $P$ & $19 / F$ & Biphasic & Not evaluated & + & ++ & NO \\
\hline 11 & $P$ & $69 / F$ & Biphasic & Absent & - & + & NO \\
\hline 12 & $P$ & $51 / \mathrm{M}$ & Biphasic & SYT-SSX 1 & + & $+++b$ & NO \\
\hline 13 & $P$ & $28 / F$ & Biphasic & SYT-SSX 1 & + & ++ & NO \\
\hline 14 & $P^{*}$ & $49 / F$ & Monophasic & SYT-SSX 1 & + & ++++ & NO \\
\hline 15 & $P^{*}$ & $30 / F$ & Monophasic & SYT-SSX 1 & + & ++ & NO \\
\hline 16 & $P^{*}$ & $55 / \mathrm{M}$ & Biphasic & SYT-SSX 1 & + & $++++b$ & NO \\
\hline 17 & $P^{*}$ & $18 / \mathrm{M}$ & Biphasic & SYT-SSX 1 & + & ++ & NO \\
\hline 18 & $P^{*}$ & $42 / \mathrm{M}$ & Biphasic & SYT-SSX 1 & + & +++ & NO \\
\hline 19 & $\mathrm{R}$ & $52 / F$ & Biphasic & SYT-SSX 2 & + & ++ & NO \\
\hline 20 & $\mathrm{R}$ & $22 / \mathrm{M}$ & Biphasic & SYT-SSX 1 & + & $++++b$ & NO \\
\hline 21 & $\mathrm{R}^{*}$ & $63 / F$ & Monophasic & SYT-SSX 1 & + & ++++ & NO \\
\hline 22 & $\mathrm{R}^{*}$ & $51 / \mathrm{M}$ & Monophasic & Not evaluated & + & ++++ & NO \\
\hline 23 & $R^{*}$ & $51 / \mathrm{M}$ & Biphasic & SYT-SSX 1 & + & ++++ & NO \\
\hline 24 & PM & $30 / \mathrm{M}$ & Monophasic & SYT-SSX 2 & + & ++++ & NO \\
\hline 25 & PM & $60 / F$ & Monophasic & SYT-SSX 2 & + & ++++ & NO \\
\hline 26 & $\mathrm{AM}^{*}$ & $51 / F$ & Monophasic & SYT-SSX 1 & + & ++++ & NO \\
\hline 27 & $\mathrm{PM}^{*}$ & $54 / F$ & Monophasic & SYT-SSX 1 & + & ++++ & NO \\
\hline 28 & $\mathrm{PM}^{*}$ & $20 / F$ & Monophasic & SYT-SSX 1 & + & +++ & NO \\
\hline 29 & $\mathrm{PM}^{*}$ & $54 / \mathrm{M}$ & Monophasic & SYT-SSX 2 & + & - & - \\
\hline 30 & $\mathrm{PM}^{*}$ & $19 / F$ & Biphasic & SYT-SSX 1 & + & ++++ & NO \\
\hline 31 & $\mathrm{PM}^{*}$ & $32 / \mathrm{M}$ & Biphasic & SYT-SSX 1 & + & +++ & NO \\
\hline 32 & $\mathrm{PM}^{*}$ & $30 / \mathrm{M}$ & Biphasic & SYT-SSX 1 & + & ++++ & NO \\
\hline 33 & $P$ & $16 / F$ & Monophasic & SYT-SSX 2 & + & +++ & NO \\
\hline 33 & $\mathrm{PM}^{*}$ & $18 / F$ & Monophasic & SYT-SSX 2 & + & + & NO \\
\hline 34 & $\mathrm{R}^{*}$ & $56 / \mathrm{M}$ & Monophasic & Not evaluated & + & ++++ & NO \\
\hline 34 & $\mathrm{PM}^{*}$ & $55 / \mathrm{M}$ & Monophasic & SYT-SSX 1 & + & +++ & NO \\
\hline
\end{tabular}

${ }^{a}$ Samples analyzed: P, primary tumor; R, tumor relapse; PM, pulmonary metastasis; AM, metastasis of the adrenal gland; samples marked with an asterisk are from pretreated patients.

${ }^{b}$ Western blot analysis in these samples revealed the presence of both the $22 \mathrm{kDa}$ and $26 \mathrm{kDa}$ splice variants of bcl-2.

ern blotting probably corresponded to the $\beta$ splice variant $22 \mathrm{kd}$ form of bcl-2, which lack the carboxyterminal transmembrane protein domain (Tsujimoto and Croce, 1986).

We used a cell line system to investigate the SS cells ability to modulate bcl-2 function through phosphorylation. The CME-1 cell line (Renwick et al, 1995), one of the few established SS cell lines available world-wide (Noguchi et al, 1997; Reeves et al, 1989; Sonobe et al, 1992, 1999), was exposed to cytotoxic concentrations of DNA-damaging agents (cisplatin and doxorubicin) and to a microtubule-stabilizing drug (taxol). As shown in Figure 3, bcl-2 was not phosphorylated in untreated cells and no drug was capable of inducing bcl-2 phosphorylation in these cells at the examined exposure times (6 and 24 hours). Under these experimental conditions, bcl-2 phosphorylation could be induced by taxol in MCF-7 cells, as expected, during an apoptotic response.

\section{Southern Blot Analysis of bcl-2 Gene Rearrangement or Amplification}

To exclude the possibility of a bcl-2 overexpression due to $B C L-2$ gene amplification or rearrangement, we performed a Southern blot analysis on seven SS cases. All samples analyzed showed the expected germinal bands (Fig. 4) when compared with the rearranged pattern of a follicular lymphoma DNA sample (data not shown), after digesting the genomic 
Table 2. Comparison of Fusion Types and Clinicopathological Variables or bcl-2 Immunoreactivity (Western Blot) in 30 SS Cases Positive for SYT-SSX RT-PCR Analysis

\begin{tabular}{|c|c|c|c|}
\hline Variable & $\begin{array}{l}S Y T-S S X 1 \\
(\mathrm{n}=20)\end{array}$ & $\begin{array}{c}S Y T-S S X 2 \\
(\mathrm{n}=10)\end{array}$ & $p$ Value $^{a}$ \\
\hline Age & & & NS \\
\hline$<30 \mathrm{yr}$ & 6 & 2 & \\
\hline$\geq 30 \mathrm{yr}$ & 14 & 8 & \\
\hline Sex & & & NS \\
\hline Male & 11 & 3 & \\
\hline Female & 9 & 7 & \\
\hline Histologic subtype & & & 0.01 \\
\hline Monophasic & 8 & 9 & \\
\hline Biphasic & 12 & 1 & \\
\hline Dimension of tumor & & & NS \\
\hline$\leq 5 \mathrm{~cm}$ & 11 & 7 & \\
\hline$>5 \mathrm{~cm}$ & 9 & 3 & \\
\hline $\begin{array}{c}\text { Primary vs. Recurrent } \\
\text { or Metastatic }\end{array}$ & & & NS \\
\hline$P$ & 10 & 5 & \\
\hline R, PM, AM & 10 & 5 & \\
\hline $\begin{array}{l}\text { bcl-2 Western Blot } \\
\text { Immunoreactivity }\end{array}$ & & & NS \\
\hline,,-+++ & 5 & 3 & \\
\hline,+++++++ & 15 & 7 & \\
\hline
\end{tabular}

${ }^{a}$ Fisher's exact test; NS, not significant.

DNAs with either HindIII or EcoRI restriction enzymes. The normalization of band intensities respective to DNA genomic fragments hybridized with a probe for $\beta$-globin also allowed us to exclude $B C L-2$ gene amplification. These results suggest that the bcl-2 constitutive expression revealed in SS is caused by other mechanisms, such as transcriptional activation and/or enhanced protein stabilization.

\section{Discussion}

Our molecular analysis of SS allow us to contribute to the clarification of the following points: i) the correlation between histologic and molecular-genetic subtypes; ii) the entity and mechanism of bcl-2 expression; and iii) the potential role of bcl-2 expression for future pharmacological developments in the treatment of SS tumors.

In keeping with previous RT-PCR-based and FISHbased studies (de Leeuw et al, 1994; Janz et al, 1995; Kawai et al, 1998; Renwick et al, 1995), we have found a tight correlation between the type of SYT-SSX fusion transcript, as determined by RT-PCR, and the monophasic SS subtype. Among 10 SYT-SSX2 carrying SS specimens analyzed (from 9 patients), 9 were monophasic tumors (90\%). We observed that, although the SYT-SSX1 fusion transcript was present in 12 of 13 biphasic SS (92\%), such a marker was also shared by 8 of 17 (47\%) monophasic SS (Table 2). We hypothesize that the SYT-SSX2 chimeric protein may prevent the tumor cells from undergoing epithelial differentiation, whereas the SYT-SSX1 protein does not inhibit this process. In fact, we cannot rule out the possibility that all SYT-SSX1-carrying SS may have been biphasic tumors where the epithelial component was missed due to inadequate sampling or small size. In three of our SS cases (patients \#12, \#17, and \#23 of Table 1) the epithelial component was serendipitously sampled, whereas in one additional case (patient \#32) it was restricted to the primary tumor. Recent FISHbased evidence shows the involvement of SSX1 in both the glandular and the connective components in biphasic SS (Birdsall et al, 1999; Nagao et al, 1996). Our own evidence of a spindle-cell restricted bcl-2 expression and its down-regulation in the epithelial component is consistent with previous reports showing that bcl-2 labeling is topographically restricted to active uncommitted cells, which need protection from apoptosis before undergoing terminal differentiation (Hockenbery et al, 1991; Lu et al, 1993b). Taken together, these data are in keeping with the clonal nature of SS spindle and epithelial cells, along with the previously referred designation of carcinosarcoma (Dardick et al, 1991; Leader et al, 1987), and give more reliability to the genetic rather than the histologic subtyping approach.

Our preliminary IHC-based observation of a constant bcl-2 expression in childhood and adulthood treated and untreated primary, recurrent, and metastatic SS (Pilotti et al, 1998) suggested a possible role of a constitutive BCL-2 gene deregulation in the pathogenesis of these tumors. Since SS is a tumor of an unknown cell of origin, a normal cell type for comparison of bcl-2 expression levels is missing. Nevertheless, with the studies on adult and embryonic normal human tissues (Hockenbery et al, 1991; Lu et al, 1993b) and comparative studies of other soft tissues spindle cell sarcomas (Hirakawa et al, 1996; Suster et al, 1998), bcl-2 [over]expression seems to be both a constitutive alteration underlying SS tumorigenesis and a useful marker in SS differential diagnosis. In the present study, we extended the previous investigations by confirming, through western blot analysis, that bcl-2 is expressed in the great majority of SS cases. Furthermore, the Southern blot analysis we performed on a subset of SS showed that BCL-2 was neither rearranged nor amplified, suggesting that the high levels of bcl-2 found in SS could be achieved through a mechanism of transcriptional gene activation and/or protein stabilization. In this context, a possible role of SYT-SSX fusion proteins in the upregulation of $B C L-2$ gene expression should be investigated. A significant correlation was not found between the levels of bcl-2 expression and the type of fusion transcript, suggesting that both SYT-SSX1 and SYT-SSX2 transcriptional factors may trigger (or be permissive for) $B C L-2$ gene activation. Additionally, the SYT-SSX4 fusion type, revealed in case \#1 only, appears to be associated with bcl-2 immunoreactivity, both by IHC and western blot analyses (Table 1). Further molecular studies are expected to elucidate the different activities, implications and/or interactions of SYT-SSX1, SYT-SSX2, and SYT-SSX4, and the role of $B C L-2$ in SS tumor onset and growth. 

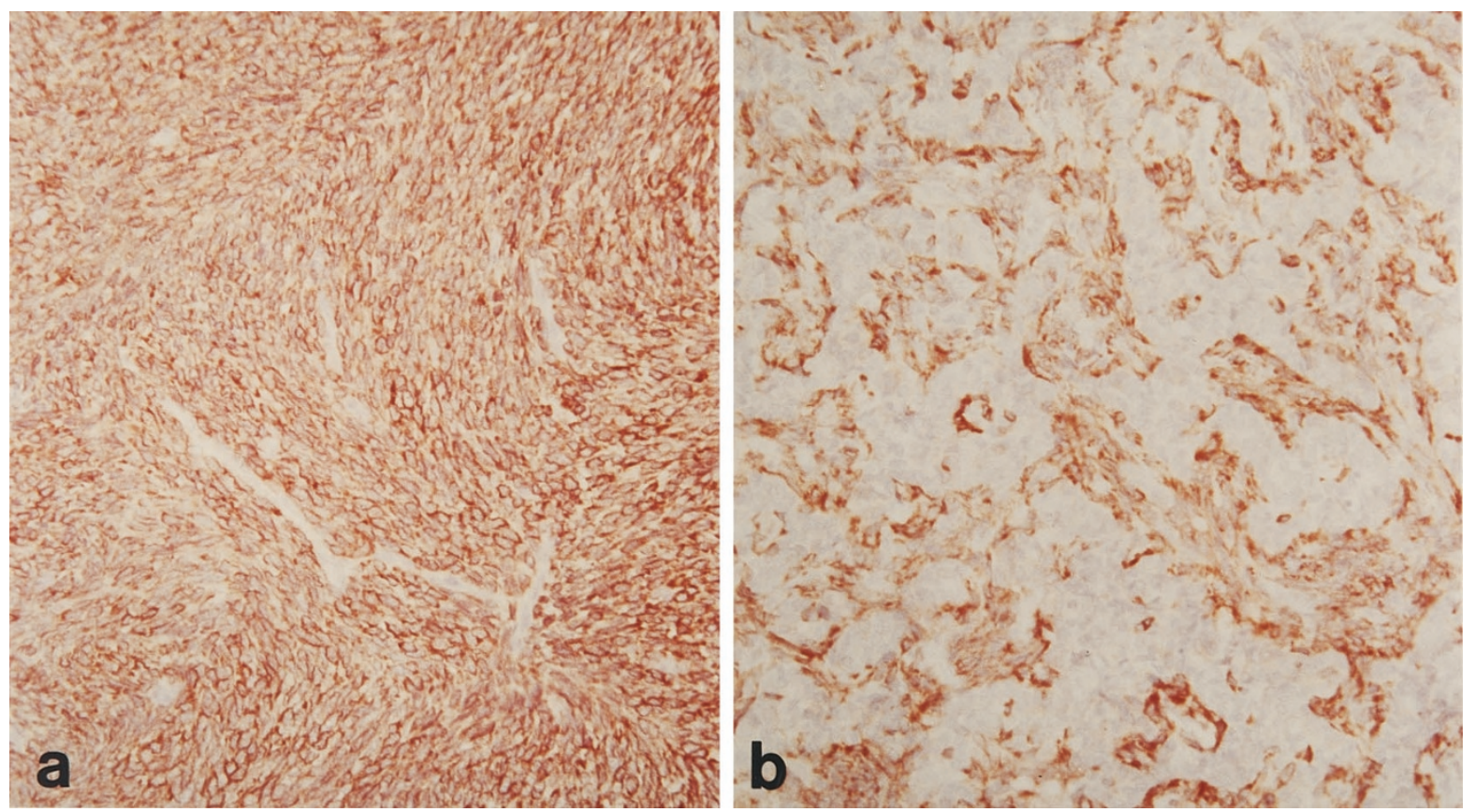

\section{Figure 1.}

IHC analysis. a: monophasic SS showing bcl-2 immunoreactivity; b: biphasic SS with bcl-2 immunoreactivity restricted to the spindle cell component.

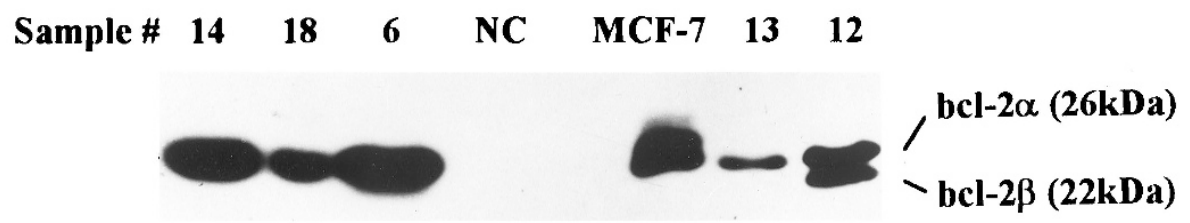

Figure 2.

Western blot analysis in SS tissue samples. Protein lysates were run on 12\% SDS-PAGE, transferred to a membrane and incubated with clone 124 anti-bcl-2 monoclonal antibody. NC: lysates from a thyroid undifferentiated carcinoma were used as negative control. MCF-7: protein samples from taxol-treated breast cancer cells served as a control for bcl-2 phosphorylation (smear of the upper part of the band). Patient \#12 shows the two bcl-2 splice variants previously described (Tsujimoto and Croce, 1986).

Two primary tumors in our SS series did not contain SYT-SSX1, SYT-SSX2, and SYT-SSX4 fusion transcripts (patients \#7 and \#11 of Table 1). Although they had been unequivocally classified as SS from a histologic/IHC standpoint, these tumors were not immunoreactive for bcl-2 by $\mathrm{IHC}$, with weak immunoreactivity in western blot analysis. It is possible that in these two cases new fusion genes, similar to SYT-SSX1, SYTSSX2, and SYT-SSX4 but not yet reported in SS, may have played a role in different gene transactivation pathways, resulting in a minor or absent activation of $B C L-2$. The involvement of other members of the SSX gene cluster at Xp11 (Chand et al, 1995; de Leeuw et al, 1996) should be investigated in order to understand the mechanisms of pathogenesis in peculiar cases such as \#7 and \#11 reported herein.

Experimental evidence suggests that inactivation of bcl-2 protein is achieved by chemotherapeutic agents acting on microtubules (ie taxol, vincristine, and vinblastine), which provoke bcl-2 inactivation via hyperphosphorylation during the G2-M phase (Haldar et al, 1996). The phosphorylation status of the bcl-2 protein, therefore, could influence the antiapoptopic properties of bcl-2, and, consequently, SS drug responsiveness. The present study, to our knowledge, is the first investigating bcl-2 phosphorylation status in SS. None of the 18 SS tissue samples from untreated primary, recurrent, and metastatic SS showed a steady-state level of bcl-2 phosphorylation when protein lysates were analyzed by western blot. This finding indicates that bcl-2 phosphorylation is not an intrinsic feature of SS. Similarly, the remaining 18 samples from patients who received a chemotherapeutic treatment were also negative for bcl-2 phosphorylation, and the CME-1 SS cell line treated in vitro with cytotoxic doses of cisplatin, doxorubicin, and taxol was also negative for bcl-2 phosphorylation. Because the surgical samples had been resected at undetermined time intervals after chemotherapy, it remains difficult to relate the effect of treatment to bcl-2 phosphorylation. Nevertheless, bcl-2 was not phosphorylated even in CME-1 cells (one of the few available established SS cell lines) that were treated in a more controlled setting. These data suggest an inability of SS cells to induce bcl-2 phosphorylation in response to a cytotoxic treatment and could provide a tentative explanation for the limited 


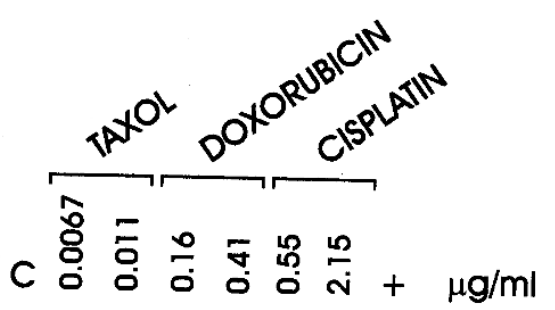

$6 h$

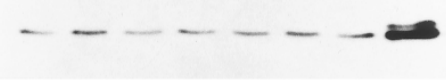

$24 \mathrm{~h}$

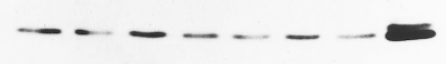

Figure 3.

Western blot analysis of bcl-2 expression in CME-1 cells. Cells were exposed to two highly cytotoxic concentrations of taxol, doxorubicin, or cisplatin for 6 or 24 hours. +: positive control for bcl-2 phosphorylation (taxol-treated MCF-7 cells). Equal amounts of proteins were loaded.

responsiveness to the conventional DNA-damaging, G1-active, ifosfamide-based, chemotherapeutic treatment of SS. On the other hand, based on our experiments with taxol treated CME-1 cells, SS tumor cell apoptosis also seems to be difficult to obtain through the bcl-2 hyperphosphorylation "unprimed" mechanism (Haldar et al, 1998), typical of G2-M active drugs. Further in vitro and/or in vivo experimental pharmacology studies are needed to investigate whether the apoptosis of SS cells is achievable by triggering bcl-2 hyperphosphorylation with other microtubule-acting chemotherapeutic agents.

In conclusion, the molecular pathogenesis of SS has been thoroughly investigated during the past years, but the network of interactions involving important molecules such as SYT-SSX1, SYT-SSX2, and SYTSSX4, transcriptionally active/inactive genes, and bcl-2 has not been completely clarified. In this regard, our data concerning bcl-2 constitutive expression and phosphorylation status are suggestive of a pathogenetic mechanism that steadily blocks apoptosis and may contribute to conventional therapy ineffectiveness.

\section{Materials and Methods}

\section{Patients and Tumors}

The accrual time of patients ranged from 1987 through 1997. However, the cases were not consecutive because only cases in which cryopreserved material was available were analyzed. The main clinical data are summarized in Table 1. Cases were from 19 females and 15 males, with ages ranging from 16 to 69 years (median age 43 years). The primary tumor/local recurrence sites were as follows: seven from thigh, four lung, three shoulder, two hand, two buttock, two neck, two groin, one feet, one elbow, and one lumbar back region. All but one (adrenal) metastases were pulmonary.

Surgical treatment consisted of local excision/wide excision in 15 primary tumors, 4 recurrences, and all
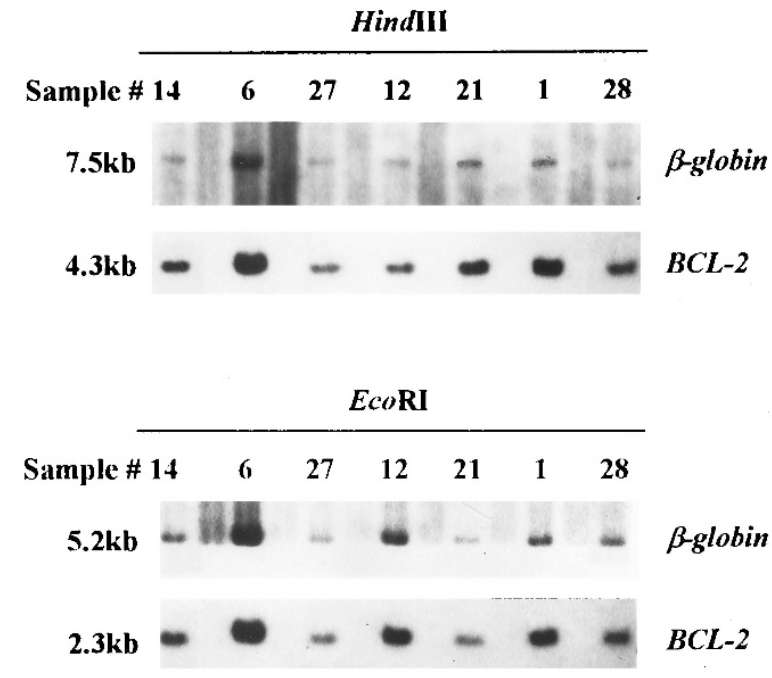

Figure 4.

Southern blot analysis. Genomic DNAs from 7 SS cases were digested with HindIII or EcoRI and hybridized with a probe against $B C L-2$ (see Materials and Methods for details). The same blots were stripped and rehybridized with a probe for $\beta$-globin.

metastases. Three patients with primary tumors and one with a recurrence underwent amputation. Five patients bearing primary tumors, four patients with recurrences, and nine patients with metastases received pre-operative chemotherapy (11 cases) or chemotherapy and radiation (7 cases). Chemotherapy regimens were based on anthracyclines plus ifosfamide as the first-line medical therapy; high dose ifosfamide was frequently employed as second line.

The samples examined consisted of primary tumors in 18 cases, local recurrences in 5 cases, and metastases in 9 cases; in two cases (\#33 and \#34), primary tumor and metastasis or recurrence and metastasis were both available and analyzed. For morphological categorization, traditional criteria (Enzinger and Weiss, 1995), recently updated (Folpe et al, 1998; Machen et al, 1999), were applied. The anti-human cytokeratin monoclonal mouse antibodies 34 $\beta$ E12 (Dako, Glostrup, Denmark, diluted 1:100) and CAM 5.2 (Becton Dickinson, San Jose, California, diluted 1:10) were used as epithelial markers with proteolitic pretreatment. Antigens were localized using standard streptavidin-biotin immunoperoxidase techniques. In three cases the epithelial component was restricted; to a single small focus ( $3 \mathrm{~mm}$ ) in one case (\#17) and to 3 foci each less than $2.2 \mathrm{~mm}$ and $3 \mathrm{~mm}$ in diameter in the two remaining cases (\#12 and \#23, respectively). In case \#32, the biphasic pattern was observed in the referred primary tumor and was absent in the pulmonary metastasis.

\section{RT-PCR Detection of SYT-SSX Fusion Transcripts}

A frozen tumor fragment from all cases as well as from two SS with the SYT-SSX1 and SYT-SSX2 fusion transcripts, respectively, representing positive controls, were mechanically disaggregated and total RNA was isolated using the RNAzolB extraction system 
(TEL-TEST, Friendswood, Texas). RNA was also extracted from normal mesenchymal tissue to be used as negative control. One $\mu \mathrm{g}$ of total RNA was reversetranscribed into cDNA using oligo(dT) primers and reverse transcriptase (Superscript, Gibco BRL, Paisley, United Kingdom) according to the manufacturer's recommendations.

Control amplification of cDNAs was accomplished by using $\beta$-actin specific primers (Adams et al, 1995). The detection of the putative SYT-SSX1 and SYTSSX2 junction regions was carried out with the forward primer: (SYT) 5'CAA CAG CAA GAT GCA TAC CA3' and with one of the following reverse primers: (SSX1) 5'GGT GCA GTT GTT TCC CAT CG3' and (SSX2) 5'GGC ACA GCT CTT TCC CAT CA3' (Kawai et al, 1998). PCR reactions consisted of denaturation at $94^{\circ} \mathrm{C}$ for 30 seconds, annealing at $58^{\circ} \mathrm{C}$ for 1 minute and elongation at $72^{\circ} \mathrm{C}$ for 1 minute. Thirtyfive cycles were performed. The putative SYT-SSX4 junction regions were detected by a nested PCR using the forward primer (SYT external): 5'CAA CAG CAA GAT GCA TAC CA3' and the reverse primer (SSX external): 5'TGC TAT GCA CCT GAT GAC GA3' in the first PCR step, and the forward primer ( $S Y T$ internal): 5'AGA CCA ACA CAG CCT GGA CCA3' and the reverse primer (SSX4): 5'GGC ACA GCT GTT TCC CAT CA3' in the second step. A thermal profile identical to that mentioned for the detection of SYT-SSX1 and SYT-SSX2 (35 cycles) was performed for both the reactions, except that the annealing temperature in the first step was $52^{\circ} \mathrm{C}$. The amplification products were analyzed on $2 \%$ agarose gel in TAE $1 \mathrm{X}$ buffer, with ethidium bromide staining and UV visualization. For the SYT-SSX1 and SYT-SSX2 positive controls, and for the single SYT-SSX4 positive case reported in the present work, RT-PCR products were sequenced on the $\mathrm{ABI} 377$ automated sequencer according to the manufacturer's instructions.

\section{Immunohistochemical Analysis of bcl-2}

Two- $\mu \mathrm{m}$ thick sections were prepared from formalinfixed, paraffin-embedded tissue samples for each SS case. Antigen retrieval by wet autoclave pretreatment (Bankfalvi et al, 1994), was performed, and tissue sections were subsequently immunostained with a 1:20 dilution of a monoclonal antibody against bcl-2 (mouse clone 124, kindly donated by Dr. Mason, Department of Histopathology, London University College) and with the streptavidin-peroxidase conjugate method (Shi et al, 1988). Sections incubated with mouse serum rather than specific antibody served as negative controls. Cytoplasmic bcl-2 reactivity, indicated as "+" in Table 1, was observed in $>75 \%$ of tumor cells in monophasic positive cases, whereas it was restricted to the spindle cell component in biphasic positive tumors.

\section{Cell Line and Culture Conditions}

The CME-1 SS cell line (Renwick et al, 1995), kindly offered by Dr. Kazmierczak (Department of Pathology,
Ziekenhuizen University, Leuven, Belgium), was cultured in RPMI-1640 medium supplemented with 10\% FCS (Life technologies, Paisley, United Kingdom). For biochemical studies, cells were seeded into $75 \mathrm{~cm}^{2}$ flasks and exposed to two highly cytotoxic drug concentrations of taxol, cisplatin, or doxorubicin after 24 hours. Cells were harvested 6 or 24 hours after the beginning of drug exposure and immediately processed for western blot analysis.

\section{Western Blot Analysis of bcl-2}

Lysates from frozen SS tissue samples and cultured cells were prepared as previously described (Perego et al, 1996). Protein samples were separated on $12 \%$ SDS-PAGE (75 $\mu \mathrm{g}$ per lane) and blotted onto Polyvynilidene Fluoride membrane (Millipore, Bedford, Massachusetts). Equal loading was checked by Ponceau staining. The MCF-7 breast cancer cell line was treated with taxol (Haldar et al, 1996), and protein lysates were run on every gel in order to provide a positive control for bcl-2 phosphorylation. A thyroid undifferentiated carcinoma, known to be immunohistochemically negative for bcl-2, was used as a negative control. A 1:100 dilution of the mouse clone 124 bcl-2 monoclonal antibody and a 1:2000 dilution of rabbit anti-mouse IgG HRP-conjugate polyclonal antibody (Sigma, St. Louis, Missouri) were used as primary and secondary antibody, respectively. bcl-2 immunoreactivity was revealed by using the ECL system (Amersham, Buckinghamshire, United Kingdom), according to the provider's instructions.

\section{Southern Blot Analysis of the BCL-2 Gene}

Genomic DNA from a subset of SS cases was isolated with standard methods and an aliquot of each sample (approximately $3 \mu \mathrm{g}$ ) was digested with EcoRI or HindIII (Boehringer Mannheim, Mannheim, Germany) following the manufacturer's instructions. DNA from a case of follicular lymphoma was used as positive control for BCL-2 gene rearrangement. All the subsequent steps were performed as already described elsewhere (Sambrook et al, 1989). Briefly, DNA fragments were separated through a $0.8 \%$ agarose gel and transferred onto a nylon membrane, which was then hybridized with a $1.5 \mathrm{kbp}{ }^{32}[\mathrm{P}]$-labeled probe encompassing a portion of chromosome 18 at the major BCL-2 breakpoint region (Cleary and Sklar, 1985). After stringent washings and X-ray film exposure, the probe was removed (Sambrook et al, 1989) and genomic DNAs rehybridized with a $325 \mathrm{bp}{ }^{32}[\mathrm{P}]-$ labeled probe for $\beta$-globin, in order to normalize band intensities for little differences in gel loading. The probe for $\beta$-globin was obtained by PCR amplification of a genomic region identified by primers $\mathrm{GH} 2 \mathrm{O}$ and KM38 (Saiki et al, 1988).

\section{Statistical Methods}

Statistical analyses were performed by means of the Statistical Analyses System package (SAS Institute, Cary, North Carolina). The variables studied included 
fusion type, age at diagnosis, sex, histologic subtype, tumor dimension, and bcl-2 western blot immunoreactivity. The independence between fusion types and the other variables were tested by Fisher's exact test $(p<0.05)$.

\section{Acknowledgements}

This study was partially supported by grants from "Associazione Italiana per la Ricerca sul Cancro" (AIRC), Milano, Italy. The authors gratefully acknowledge Dr. Kazmierczak (Department of Pathology, Ziekenhuizen University, Leuven, Belgium) who provided the CME-1 cell line and Dr. Mason (Department of Histopathology, London University College) who donated the mouse clone 124 anti-bcl-2 monoclonal antibody. They also thank Mrs. Marina Sperni for reviewing the English format of the manuscript and $\mathrm{Mr}$. Mario Azzini for photographic assistance.

\section{References}

Adams V, Kempf W, Hassam S, and Briner J (1995). Determination of hexokinase isoenzyme I and II composition by RT-PCR: Increased hexokinase isoenzyme II in human renal cell carcinoma. Biochem Mol Med 54:53-58.

Apakama I, Robinson MC, Walter NM, Charlton RG, Royds JA, Fuller CE, Neal DE, and Hamdy FC (1996). bcl-2 overexpression combined with $\mathrm{p} 53$ protein accumulation correlates with hormone-refractory prostate cancer. $\mathrm{Br} \mathrm{J}$ Cancer 74: 1258-1262.

Bakhshi A, Jensen JP, Goldman P, Wright JJ, McBride OW, Epstein AL, and Korsmeyer SJ (1985). Cloning the chromosomal breakpoint of $t(14 ; 18)$ human lymphomas: Clustering around $\mathrm{JH}$ on chromosome 14 and near a transcriptional unit on 18. Cell 41:899-906.

Bankfalvi A, Navabi H, Bier B, Bocker W, Jasani B, and Schmid KW (1994). Wet autoclave pretreatment for antigen retrieval in diagnostic immunohistochemistry. J Pathol 174: 223-228.

Birdsall S, Osin P, Lu YJ, Fisher C, and Shipley J (1999). Synovial sarcoma specific translocation associated with both epithelial and spindle cell components. Int J Cancer 82:605608.

Brett D, Whitehouse S, Antonson P, Shipley J, Cooper C, and Goodwin $G$ (1997). The SYT protein involved in the $t(X ; 18)$ synovial sarcoma translocation is a transcriptional activator localised in nuclear bodies. Hum Mol Genet 6:1559-1564.

Chand A, Clark J, Cooper CS, and Craig IW (1995). Longrange organization of reiterated sequences, including the SSX1 cDNA at the OATL1 cluster in Xp11.23. Genomics 30:545-552.

Clark J, Rocques PJ, Crew AJ, Gill S, Shipley J, Chan AM, Gusterson BA, and Cooper CS (1994). Identification of novel genes, SYT and SSX, involved in the $t(X ; 18)(p 11.2 ; q 11.2)$ translocation found in human synovial sarcoma. Nat Genet 7:502-508.

Cleary ML and Sklar J (1985). Nucleotide sequence of a $t(14 ; 18)$ chromosomal breakpoint in follicular lymphoma and demonstration of a breakpoint-cluster region near a transcriptionally active locus on chromosome 18. Proc Natl Acad Sci USA 82:7439-7443.
Crew AJ, Clark J, Fisher C, Gill S, Grimer R, Chand A, Shipley J, Gusterson BA, and Cooper CS (1995). Fusion of SYT to two genes, SSX1 and SSX2, encoding proteins with homology to the Kruppel-associated box in human synovial sarcoma. EMBO J 14:2333-2340.

Dardick I, Ramjohn S, Thomas MJ, Jeans D, and Hammar SP (1991). Synovial sarcoma. Inter-relationship of the biphasic and monophasic subtypes. Pathol Res Pract 187:871-885.

de Leeuw B, Balemans M, and Geurts van Kessel A (1996). A novel Kruppel-associated box containing the SSX gene (SSX3) on the human X chromosome is not implicated in $t(X ; 18)$-positive synovial sarcomas. Cytogenet Cell Genet 73:179-183.

de Leeuw B, Balemans M, Olde Weghuis D, and Geurts van Kessel $A$ (1995). Identification of two alternative fusion genes, SYT-SSX1 and SYT-SSX2, in $\mathrm{t}(\mathrm{X} ; 18)(\mathrm{p} 11.2 ; \mathrm{q} 11.2)$-positive synovial sarcomas. Hum Mol Genet 4:1097-1099.

de Leeuw B, Suijkerbuijk RF, Olde Weghuis D, Meloni AM, Stenman G, Kindblom LG, Balemans M, van den Berg E, Molenaar WM, Sandberg AA, and Geurts Van Kessel A (1994). Distinct Xp11.2 breakpoint regions in synovial sarcoma revealed by metaphase and interphase FISH: Relationship to histologic subtypes. Cancer Genet Cytogenet 73:89-94.

dos Santos NR, de Bruijn DR, Balemans M, Janssen B, Gartner F, Lopes JM, de Leeuw B, and Geurts van Kessel A (1997). Nuclear localization of SYT, SSX and the synovial sarcoma-associated SYT-SSX fusion proteins. Hum Mol Genet 6:1549-1558.

Enzinger FM and Weiss SW (1995). Synovial sarcoma. In: Enzinger FM and Weiss SW, editors. Soft Tissue Tumours, $3^{\text {rd }}$ ed. St Louis: Mosby, 757-786.

Ferrieres G, Cuny M, Simony-Lafontaine J, Jacquemier J, Rouleau C, Guilleux F, Grenier J, Rouanet P, Pujol H, Jeanteur $P$, and Escot $C$ (1997). Variation of bcl-2 expression in breast ducts and lobules in relation to plasma progesterone levels: Overexpression and absence of variation in fibroadenomas. J Pathol 183:204-211.

Folpe AL, Schmidt RA, Chapman D, and Gown AM (1998). Poorly differentiated synovial sarcoma: Immunohistochemical distinction from primitive neuroectodermal tumors and high-grade malignant peripheral nerve sheath tumors. Am J Surg Pathol 22:673-682.

Haldar S, Basu A, and Croce CM (1998). Serine-70 is one of the critical sites for drug-induced $\mathrm{Bcl} 2$ phosphorylation in cancer cells. Cancer Res 58:1609-1615.

Haldar S, Chintapalli J, and Croce CM (1996). Taxol induces bcl-2 phosphorylation and death of prostate cancer cells. Cancer Res 56:1253-1255.

Hirakawa N, Naka T, Yamamoto I, Fukuda T, and Tsuneyoshi M (1996). Overexpression of bcl-2 protein in synovial sarcoma: A comparative study of other soft tissue spindle cell sarcomas and an additional analysis by fluorescence in situ hybridization. Hum Pathol 27:1060-1065.

Hockenbery DM, Zutter M, Hickey W, Nahm M, and Korsmeyer SJ (1991). BCL2 protein is topographically restricted in tissues characterized by apoptotic cell death. Proc Natl Acad Sci USA 88:6961-6965.

Janz M, De Leeuw B, Weghuis DO, Werner M, Nolte M, Geurts Van Kessel A, Nordheim A, and Hipskind RA (1995). Interphase cytogenetic analysis of distinct X-chromosomal translocation breakpoints in synovial sarcoma. J Pathol 175:391-396. 
Kawai A, Woodruff J, Healey JH, Brennan MF, Antonescu CR, and Ladanyi M (1998). SYT-SSX gene fusion as a determinant of morphology and prognosis in synovial sarcoma. N Engl J Med 338:153-160.

Korsmeyer SJ (1992). Bcl-2 initiates a new category of oncogenes: Regulators of cell death. Blood 80:879-886.

Leader M, Patel J, Collins M, and Kristin H (1987). Synovial sarcomas. True carcinosarcomas? Cancer 59:2096-2098.

Lu QL, Elia G, Lucas S, and Thomas JA (1993a). Bcl-2 proto-oncogene expression in Epstein-Barr-virus-associated nasopharyngeal carcinoma. Int J Cancer 53:29-35.

Lu QL, Poulsom R, Wong L, and Hanby AM (1993b). Bcl-2 expression in adult and embryonic non-haematopoietic tissues. J Pathol 169:431-437.

Machen SK, Easley KA, and Goldblum JR (1999). Synovial sarcoma of the extremities: A clinicopathologic study of 34 cases, including semi-quantitative analysis of spindled, epithelial, and poorly differentiated areas. Am J Surg Pathol 23:268-275.

Nagao K, Ito H, and Yoshida H (1996). Chromosomal translocation $t(X ; 18)$ in human synovial sarcomas analysed by fluorescence in situ hybridization using paraffin-embedded tissue. Am J Pathol 148:601-609.

Noguchi SI, Ueki T, Kawauchi S, Fukuda T, Matsuura H, Sonoda T, and Tsuneyoshi M (1997). Establishment and characterization of a new synovial sarcoma cell line, SNSY-1: Special reference to bcl-2 protein and SYT-SSX1 hybrid transcripts. Int J Cancer 72:995-1002.

Perego P, Giarola M, Righetti SC, Supino R, Caserini C, Delia D, Pierotti MA, Miyashita T, Reed JC, and Zunino F (1996). Association between cisplatin resistance and mutation of p53 gene and reduced bax expression in ovarian carcinoma cell systems. Cancer Res 56:556-562.

Pezzella F, Turley H, Kuzu I, Tungekar MF, Dunnill MS, Pierce CB, Harris A, Gatter KC, and Mason DY (1993). bcl-2 protein in non-small-cell lung carcinoma. N Engl J Med 329:690694.

Pilotti S, Mezzelani A, Azzarelli A, Rilke F, and Pierotti MA (1998). bcl-2 expression in synovial sarcoma. J Pathol 184: 337-339.

Reed JC (1994). Bcl-2 and the regulation of programmed cell death. J Cell Biol 124:1-6.

Reeves BR, Smith S, Fisher C, Warren W, Knight J, Martin C, Chan AM, Gusterson BA, Westbury G, and Cooper CS (1989). Characterization of the translocation between chromosomes $X$ and 18 in human synovial sarcomas. Oncogene 4:373-378.

Renwick PJ, Reeves BR, Dal Cin P, Fletcher CD, Kempski H, Sciot R, Kazmierczak B, Jani K, Sonobe H, and Knight JC (1995). Two categories of synovial sarcoma defined by divergent chromosome translocation breakpoints in Xp11.2, with implications for the histologic sub-classification of synovial sarcoma. Cytogenet Cell Genet 70:58-63.
Saiki RK, Gelfand DH, Stoffel S, Scharf SJ, Higuchi R, Horn GT, Mullis KB, and Erlich HA (1988). Primer-directed enzymatic amplification of DNA with a thermostable DNA polymerase. Science 239:487-491.

Sambrook J, Fritsch EF, and Maniatis T (1989). Molecular Cloning: A Laboratory Manual, $2^{\text {nd }}$ ed. New York: Cold Spring Harbor Laboratory Press.

Shi ZR, Itzkowitz SH, and Kim YS (1988). A comparison of three immunoperoxidase techniques for antigen detection in colorectal carcinoma tissues. J Histochem Cytochem 36: 317-322.

Skytting B, Nilsson G, Brodin B, Xie Y, Lundeberg J, Uhlen M, and Larsson O (1999). A novel fusion gene, SYT-SSX4, in synovial sarcoma. J Natl Cancer Inst 91:974-975.

Sonobe H, Manabe Y, Furihata M, Iwata J, Oka T, Ohtsuki Y, Mizobuchi H, Yamamoto H, Kumano O, and Abe S (1992). Establishment and characterization of a new human synovial sarcoma cell line, HS-SY-II. Lab Invest 67:498-505.

Sonobe H, Takeuchi T, Liag SB, Taguchi T, Yuri K, Shimizu K, Iwata J, Furihata M, Ohtsuki Y, and Testa JR (1999). A new human synovial sarcoma cell line, HS-SY-3, with a truncated form of hybrid SYT/SSX1 gene. Int J Cancer 82:459-464.

Sreekantaiah C, Ladanyi M, Rodriguez E, and Chaganti RS (1994). Chromosomal aberrations in soft tissue tumours. Relevance to diagnosis, classification, and molecular mechanisms. Am J Pathol 144:1121-1134.

Suster S, Fisher C, and Moran CA (1998). Expression of bcl-2 oncoprotein in benign and malignant spindle cell tumours of soft tissue, skin, serosal surfaces, and gastrointestinal tract. Am J Surg Pathol 22:863-872.

Taskin M, Lallas TA, Barber HR, and Shevchuk MM (1997). bcl-2 and p53 in endometrial adenocarcinoma. Mod Pathol 10:728-734.

Tilly JL (1996). Apoptosis and ovarian function. Rev Reprod $1: 162-172$

Tsujimoto Y, Cossman J, Jaffe E, and Croce CM (1985). Involvement of the bcl-2 gene in human follicular lymphoma. Science 228:1440-1443.

Tsujimoto $Y$ and Croce CM (1986). Analysis of the structure, transcripts, and protein products of bcl-2, the gene involved in human follicular lymphoma. Proc Natl Acad Sci USA 83:5214-5218. 